\title{
In-silico study of Agaricus Bisporus on DNA damaging protein
}

\author{
Sanket B. Shelke', Dr. Pravin Badhe ${ }^{2}$ \\ ${ }^{1}$ Student, Department of Pharmacy, Navsahyadri Institute of Pharmacy, Pune, INDIA. \\ ${ }^{2}$ Associate Professor, Pharmaceutics department, Navsahyadri Institute of Pharmacy, Pune, INDIA. \\ Corresponding author's mail- $\underline{\text { sanketshelke.ss21@gmail.com }}$
}

\begin{abstract}
-
Agaricus bisporus is belonging to family agaricaceae, which is widely acceptable and mostly cultivated among the all mushrooms. It has great nutritional values and it is rich in proteins, vitamins, carbohydrates, fibers, minerals and amino acids. It is effective in antimicrobial, anticancer, antidiabetic, antihypercholesterolemic, antihypertensive, hepatoprotective and antioxidant activities. As it is effective in anticancer property, we check the effects of chemical constituents of Agaricus Bisporus on DNA damaging protein which results its activity PARP inhibiting or vise-versa.
\end{abstract}

We choose the molecular docking technique to check the effects of different chemical constituents of Agaricus Bisporus on DNA damaging protein. For that different PARP inhibitory drugs taken as the standard. We perform the molecular docking of the chemical constituents of Agaricus Bisporus, using 4UND protein with the help of PyRx software and BIOVIA Discovery studio software. Along with that PARP inhibitor drugs also run against the same protein.

The results of molecular docking shows the some of the constituents of Agaricus Bisporus has better binding affinity than the standard taken PARP inhibitor drugs. The ergosterol shows the better binding affinity than the niraparib and rucaparib on the same proteins. On other hands the naringenin, quercetin, anthocyanin, folate and myricetin shows the better results than the rucaparib. That means the ergosterol shows the better results as PARP inhibitor than the niraparib and rucaparib.

\section{Keywords:-}

Agaricus Bisporus, Button Mushroom, Molecular docking, PyRx software, BIOVIA Discovery studio.

\section{Introduction :-}


Agaricus Bisporus is the mushroom is cultivated all over the world [01] in every ascetic except Antarctica [02]. It is most dominating and most cultivated in all over the mushroom [03,04]. It is rich in the proteins, carbohydrates, lipids, fibers, polyphenols, flavonoids, minerals, vitamins [05,06,07]. It also contains phenolic acids [08,09], fatty acids [10], flavonoids [11], essentials amino acid and non-essential amino acids [12]. Agaricus Bisporus is belonging to the to family agaricaceae[06]. It have been found effective in antimicrobial, anticancer, antidiabetic, antihypercholesterolemic, antihypertensive, hepatoprotective and antioxidant activities.[13] Apart from food and food beverages it has a role in perfumery, cosmetic industries and pharmaceutical industries [14]. As it has anticancer activity, we should perform the molecular docking on the chemical constituents of Agaricus Bisporus.

Molecular docking is the methodology that explores the responses of small molecules in the binding site of a targeted protein [15]. Molecular docking is a important tool in structural molecular biology and computer-assisted drug design. The goal of ligand-protein docking is to predict the binding of ligand with a protein of known three-dimensional structure [16]. Molecular docking is the computer-based approach for identification of bound conformation and prediction of binding affinity of ligands to protein [17].

The purpose of this study to know about the binding affinity of constituents of Agaricus Bisporus on the DNA damaging protein and compare with the standard PARP inhibitor drugs to check the binding affinity.

\section{Materials and methods:-}

\subsection{Materials-}

PyRx is written in Python programming language and it can run on nearly any modern computer, from PC (personal computer) to supercomputer. This methods also work on Linux and Mac OS as well.

\subsection{1] Software and hardware-}

i) PyRx software consisting of AutoDock and AutoDockvina [18]

ii) BIOVIA Discovery Studio 2021 v21.1.0.20298 [19] 
iii) HP 15s-fr2006TU, Intel core i3-1115G4 processor, 512 GB SSD, 8GB SODIMM DDR4 SDRAM, $11^{\mathrm{TH}}$ Gen, Windows 10 .

\subsection{2] Input Files-}

To start with structure-based virtual screening, structures of the target macromolecule and small molecules are needed as input files. For that there are different websites available where we can download these input files. We used PubChem website to get 3D structure of small molecules in the 'sdf' format which are chemical constituents of Agaricus Bisporus [20], and Protein Data Bank to get 3D structures of macromolecule that is protein in '.pdb' format [21].

Vitamin C, Thiamine, Riboflavin, Niacin, Pantothenic acid, Vitamin B $_{6}$, Folate, Betaine, Vitamin $\mathrm{B}_{12}$, Vitamin $\mathrm{E}$, Tocopherol (beta, gamma, delta), Vitamin $\mathrm{D}_{2}$ and Vitamin $\mathrm{D}_{3}$ [05,06], ergothioneine [22], Gallic acid, Caffeic acid, Protocatechuic acid, p-Hydroxybenzoic acid, p-Coumaric acid, Cinnamic acid, Homogentisic acid, chlorogenic acid and ferulic acid [08,09,23], ergosterol [24], conjugated linoleic acid, linoleic, palmitic acid, stearic acid [10], anthocyanin, myricetin, quercetin, kaempferol, naringenin, catechin, and resveratrol [11] are the chemical constituents of Agaricus Bisporus are taken for molecular docking.

i] For small molecules (ligands)-

The chemical constituents of button mushroom i.e. ligands were downloaded from the PubChem site in 3d structure with the ".sdf" format. Open PubChem website and search their respective molecules and then click on download button, from that select 3D SDF: Save. In similar way we can downloaded all required molecules.

ii] For macromolecule-

protein is selected for molecular docking and it was downloaded from the protein data bank in ".pdb" format. Open RCSB PDB homepage and search our protein their with code 4UND and click on Download Files, and select PDB Format.

Here we selected PARP-1 i.e. '4UND' protein which are responsible for DNA damaging. It promotes the cancer growth and progression. For that different PARP inhibitors drugs are available in market; from that Olaparib, rucaparib, talazoparib and niraparib are 
taken as standard for molecular docking. Here we check that is chemical constituents of agaricus bisporus has binding with that protein and shows better results or not. Our hypothesis is that chemical constituents of Agaricus Bisporus may shows better results than the PARP-1 inhibitors drugs (rucaparib, talazoparib and niraparib) on 4UND protein.

\section{2] Methods-}

\subsection{1] Prepare input files for docking-}

\section{A] Ligands-}

The PDBQT file format suitable for docking for virtual screening in AutoDock Vina. For that input files can be used for virtual screening must be converted to PDBQT format by using open babel.

1. Start by double-clicking on PyRx icon on the Desktop.

2. Select Open Babel tab under Controls panel and click on the first icon on its toolbar with plus (+) sign on it. Navigate to the Downloads folder and select the standard PARP inhibitor.

3. Click on the first icon on the Open Babel toolbar again, and select all small molecules one by one in same manner. If other molecules are to be included in virtual screening, the Open Babel widget can be used to convert them to PDBQT file format.

4. Select the any molecule from the list and right-click and use the Minimize all option. Click $\mathrm{OK}$ and wait for energy minimization to complete. After that the title of this molecule has changed. The '_uff' part corresponds to the force field used for energy minimization, which, by default, is the Universal Force Field as implemented in Open Babel software package.

5. Right-click on any of the rows in Open Babel table and use Convert All to AutoDock Ligand (pdbqt). This will create pdbqt files corresponding molecules under the Ligands folder.

6. this files automatically added in autodock ligand panel.

\section{B] Macromolecule-}

Before taking in PyRx software we should want to remove some unessential part of protein. For that BIOVIA Discovery studio software is necessary. 
1. Start by double-clicking on BIOVIA Discovery studio icon on the Desktop.

2. select file tab and then click on open. It navigate to the downloads folder and select the 4UND.pdb file. After that we can see the protein on screen.

3. Then click on view tab and select hierarchy. It shows the all content of our protein.

4. Click on water and go to edit tab and delete it. In same way you should delete hetatm and unrequired other chains.

5.After that click on Chemistry tab and select hydrogen and then add polar. This way you should add polar hydrogen atom.

6. Now we save this file in pdb format and it replace the existing protein file.

7. Open PyRx software and then click on File $\rightarrow$ Load Molecule menu and open 4und.pdb file. Right-click on 4und under Molecules panel and select AutoDock $\rightarrow$ Make Macromolecule.

\subsection{2] Run Virtual Screening Using Vina Wizard-}

1. Select Vina Wizard tab under the Controls panel of PyRx and click on the Start button.

2. Select Ligands from ligand folder. (use the control key for selecting multiple ligands)

3. Select 4und under the Macromolecules folder and click on the Forward button on Vina Wizard.

4. After that we see the white grid box with spherical handles on protein molecular structure. Make sure that selected grid box size big enough to allow the ligand to move freely. For that Click on the Maximize button under Vina Search Space, then click on the Forward button.

5.This starts AutoDock Vina and docks each ligand, one by one, to 4und. It takes few minutes to complete this virtual screening on a laptop.

6. After virtual screening is completed, PyRx automatically advances to Analyze Results page, where results of virtual screening computation can be viewed.

7. PyRx users can also export virtual screening results as CSV (Comma-Separated Values) or SDF files. This is useful for further analysis, filtering, or re-ranking of virtual screening results. 


\section{Results from docking-}

Table 1 shows the binding affinity of different receptors on '4UND' binding protein.

\begin{tabular}{|c|c|c|}
\hline Complex (protein+ligand) & ligands & $\begin{array}{c}\text { Binding Affinity } \\
\text { (K cal/mol) }\end{array}$ \\
\hline A] Standard \\
\hline 4und_135565082_uff_E=560.92 & Talazoparib & $\mathbf{- 1 0 . 7}$ \\
\hline 4und_9931954_uff_E=653.31 & Rucaparib & $\mathbf{- 9 . 2}$ \\
\hline \multicolumn{2}{|c|}{ B] Chemical constituents } \\
\hline 4und_444679_uff_E=607.36 & Ergosterol \\
\hline 4und_932_uff_E=195.80 & Naringenin & $\mathbf{- 9 . 8}$ \\
\hline 4und_135398658_uff_E=289.04 & Folate & $\mathbf{- 9 . 4}$ \\
\hline 4und_145858_uff_E=178.56 & Anthocyanin & $\mathbf{- 9 . 3}$ \\
\hline 4und_5280343_uff_E=380.43 & Quercetin & $\mathbf{- 9 . 3}$ \\
\hline 4und_5281672_uff_E=388.01 & Myricetin & $\mathbf{- 9 . 3}$ \\
\hline
\end{tabular}

\section{Table 1}

The docking results of remaining constituents of Agaricus Bisporus are shown in appendix table 3.

From the docking results, it is shown that the binding affinity of ergosterol(-9.8 Kcal/mol) which is chemical constituent of Agaricus Bisporus is better than the rucaparib(-9.2 $\mathrm{Kcal} / \mathrm{mol})$ and equals to the niraparib(-9.8 Kcal/mol). Both niraparib and rucaparib are the standard PARP inhibitor drugs and the ergosterol shows the better binding affinity than them. Also, the naringenin, quercetin, anthocyanin and folate are the constituents which shows better binding affinity than the rucaparib; whereas the Myricetin shows the same binding affinity as rucaparib.

\section{Diagrams of molecular docking:}



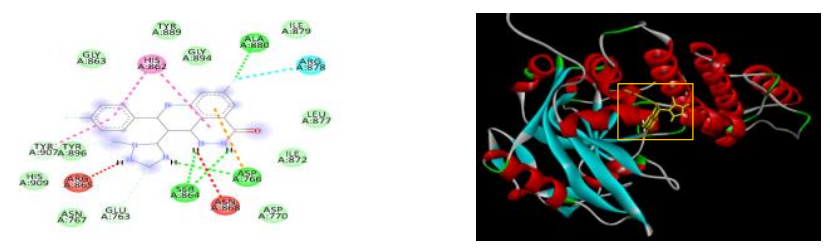

2D

Talazoparib

3D

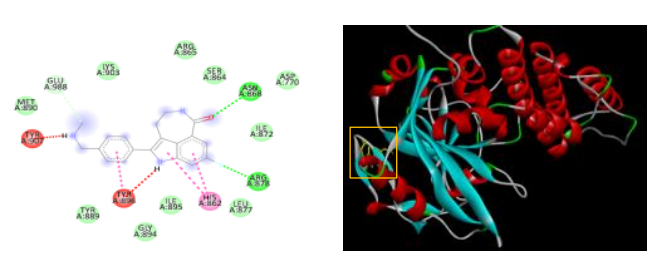

2D Rucaparib 3D

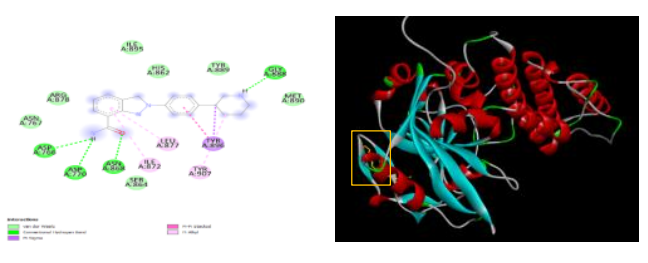

2D Niraparib

3D

\section{Fig.2- 2D \& 3D images of standard PARP inhibitor drugs binding with 4UND protein}

Fig.2 shows the 2D \& 3D images of molecular docking of standard PARP inhibitor drugs that binds to 4UND protein. In each 3D diagram, yellow structure is ligand and remaining all structure is of protein; yellow box shows the binding site of respective ligand on 4UND protein.

In 2D diagram of talazoparib, it formed 8 hydrogen bonds with SER864, ASN868, ALA880, TYR896, ASP766, GLU763, ARG878 of the target protein. It forms hydrophobic bonds with HIS862, TYR907, ALA880, ASP766 of the target site. In 2D diagram of rucaparib, it formed 5 hydrogen bonds with TYR907, TYR896, ARG878, ASN868, GLU988 of the target protein. It forms hydrophobic bonds with HIS862, ARG878, ASN868, TYR896 of the target site. In 2D diagram of niraparib, it formed 4 hydrogen bonds with ASP766, ASP770, ASN868, GLY888 of the target protein. It forms hydrophobic bonds with TYR896, TYR907, ILE872, LEU877 of the target site. 


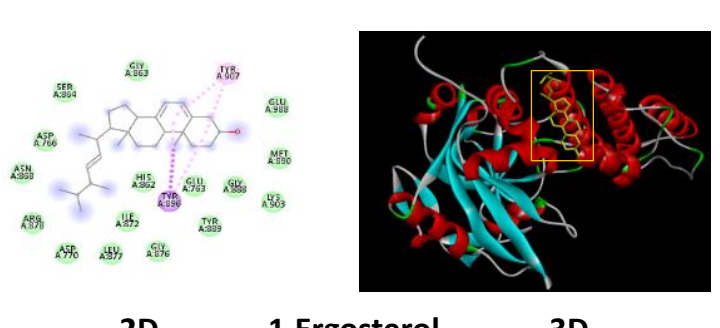

2D 1.Ergosterol 3D
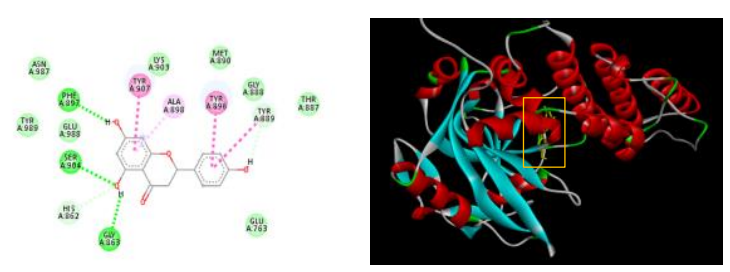

2D 2.Naringenin

3D

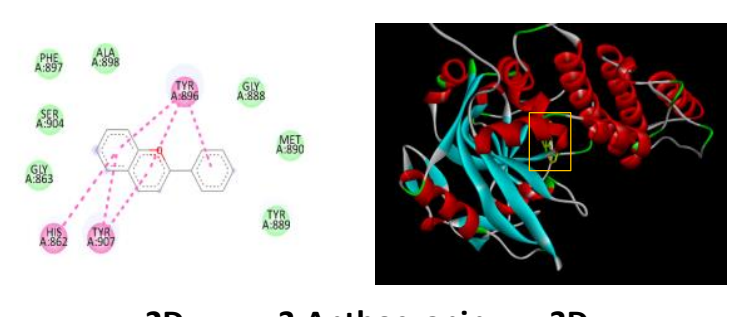

2D 3.Anthocyanin 3D
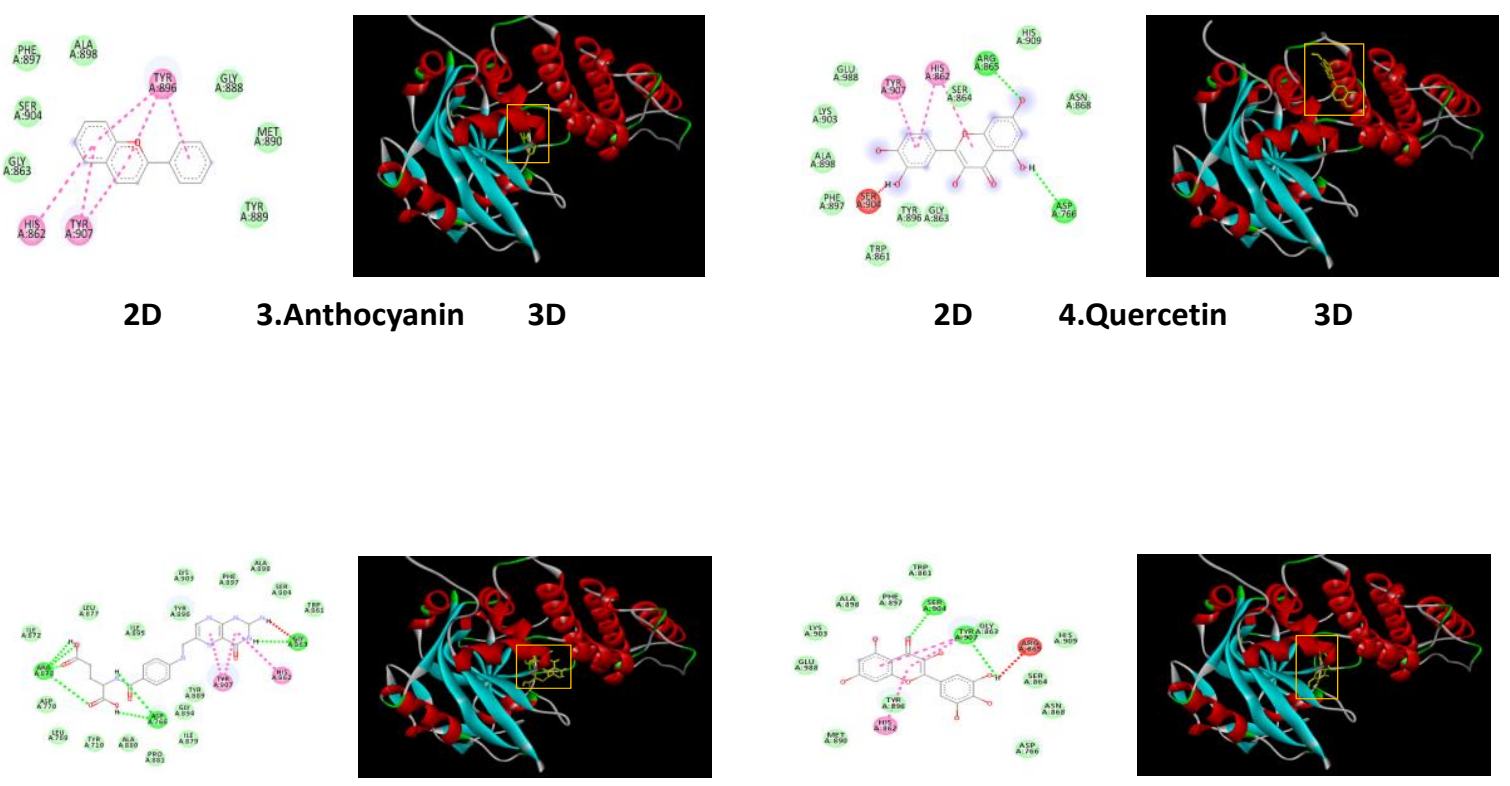

5. Folate

3D

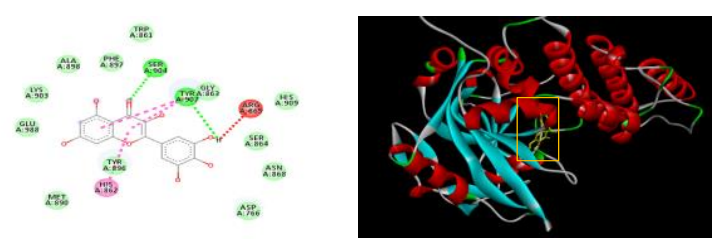

2D

6. Myricetin

3D

Fig.3- 2D \& 3D images of Chemical Constituents of Agaricus Bisporus binding with 4UND protein

Fig. 3 shows the 2D \& 3D images of molecular docking of chemical constituents of Agaricus Bisporus that binds to $4 \mathrm{UND}$ protein. In each 3D diagram, yellow structure is ligand and remaining all structure is of protein; yellow box shows the binding site of respective ligand on 4UND protein.

The remaining 2D \& 3D images of constituents of Agaricus Bisporus with 4UND protein are added in appendix section. 


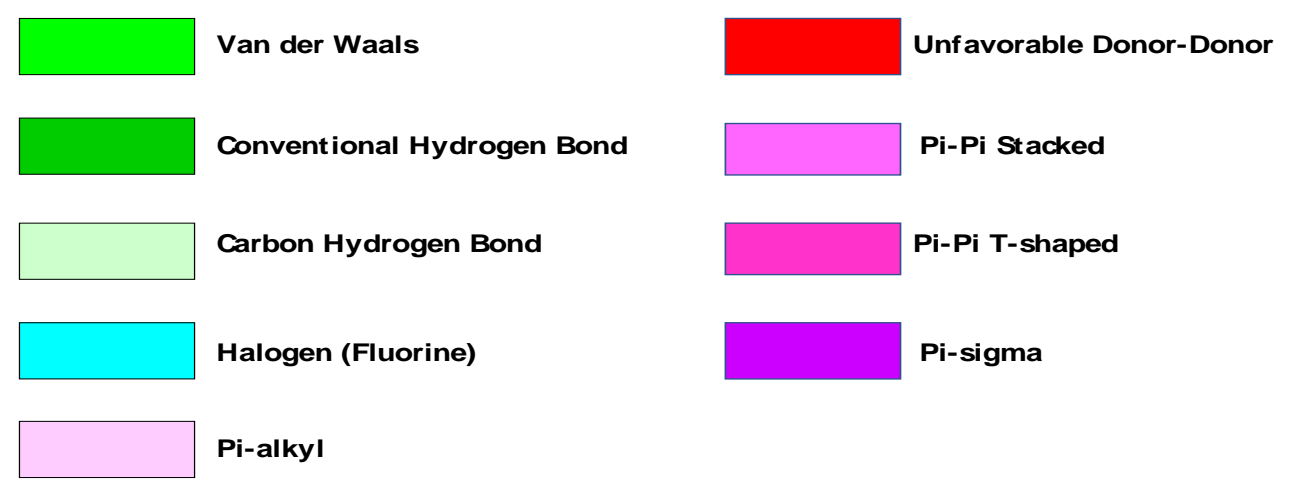

\section{Interactions shown in all 2D images}

In 2D diagram of ergosterol, it forms hydrophobic bonds with TYR896, TYR907 of the target site of 4UND protein. In 2D diagram of naringenin, it formed 5 hydrogen bonds with PHE897, SER904, GLY863, HIS862, TYR889 of the target protein. It forms hydrophobic bonds with TYR907, ALA898, TYR896, TYR889 of the target site. In 2D diagram of anthocyanin, it forms hydrophobic bonds with HIS862, TYR907, TYR896 of the target site. In 2D diagram of quercetin, it formed 3 hydrogen bonds with SER904, ASP766, ARG865 of the target protein. It forms hydrophobic bonds with HIS862, TYR907 of the target site. In 2D diagram of folate, it formed 8 hydrogen bonds with ARG878, ASP766, GLY863 of the target protein. It forms hydrophobic bonds with HIS862, TYR907, GLY863 of the target site. In 2D diagram of myricetin, it formed 3 hydrogen bonds with SER904, TYR907, ARG865 of the target protein. It forms hydrophobic bonds with HIS862, TYR907 of the target site.

\section{Discussion:-}

From the results it shows that, comparison of all the chemical constituents of Agaricus Bisporus and the standard PARP inhibitor drugs on the basis of binding energy criteria on PARP protein (4UND), we get that the ergosterol shows the best binding affinity among the all chemical constituents of Agaricus Bisporus and also better than the niraparib and rucaparib. Some of the constituents like naringenin, quercetin, anthocyanin, folate and myricetin are shows better binding affinity than the rucaparib. 
Rucaparib is an anti-cancer agent used to treat recurrent ovarian, fallopian tube, or peritoneal cancer [25,26]; and the Niraparib is a poly-ADP ribose polymerase inhibitor used to treat recurrent epithelial ovarian, fallopian tube, or primary peritoneal cancer responding to platinum-based chemotherapy [27,28].

Ergosterol is useful in the cancer therapy as it inhibits the cancer growth [29]. Its also effective in breast cancer [30]. So, it has the anticancer activity. It may show the better results over the PARP inhibitor drugs on DNA damaging protein.

\section{Conclusion :-}

The analysis of molecular docking helps to examine and evaluate the binding of different chemical constituents of the Agaricus Bisporus. Among the all-tested constituents ergosterol were found to be the most potential constituent of Agaricus Bisporus which possess the better binding affinity to ‘4UND' PARP protein among all other constituents.

From the results it can be concluded that the binding affinity of ergosterol which is chemical constituent of Agaricus Bisporus is better than the rucaparib and equals to the niraparib. Both niraparib and rucaparib are the standard PARP inhibitor drugs and the ergosterol shows the better binding affinity than them. Also, the naringenin, quercetin, anthocyanin \& folate are the constituents which shows better binding affinity than the rucaparib.

\section{Reference:-}

[01] Anna Szabó, Júlia Györfi, András Geösel, "Enhancing the vitamin-D concentration in white button mushrooms by UV light", 45 th Croatian \& 5 th International Symposium on Agriculture, 599-603.

[02] Andersson HC, Gry J. Phenyl Hydrazines in the Cultivated Mushroom Agaricus bisporus Occurrence, Biological Properties, Risk Assessment and Recommendations. Nordic Council of Ministers, Copenhagen. Tema Nord 558, Ekspressen Tryk \& Kopicenter; 2004. p. $1-123$.

[03] Karthick K, Dr. Hamsalakshmi, "Current scenario of mushroom industry in India", International Journal of Commerce and Management Research, Volume 3; Issue 3; March 2017; Page No. 23-26. 
[04] Callac P, Imbernon M, Guinberteau J. Discovery of a wild Mediterranean population of Agaricus bisporus, and its usefulness for breeding work. Mushroom Sci 2000;15: 245-252.

[05] Sang Chul Jeong, Yong Tae Jeong, Byung Keun Yang, Rezuanul Islam, Sundar Rao Koyyalamudia , Gerald Pang, Kai Yip Cho, Chi Hyun Song, "White button mushroom (Agaricus bisporus) lowers blood glucose and cholesterol levels in diabetic and hypercholesterolemic rats", Nutrition Research 30 (2010) 49-56.

[06] Apoorva Bhushan, Mayank Kulshreshtha, "The Medicinal Mushroom Agaricus bisporus: Review of Phytopharmacology and Potential Role in the Treatment of Various Diseases", Journal of Nature and Science of Medicine : Volume 1 Issue 1 I January-June 2018.

[07] Hojat Ghahremani-Majd and Farshad Dashti, "Chemical Composition and Antioxidant Properties of Cultivated Button Mushrooms (Agaricus bisporus)", Hort. Environ. Biotechnol. 56(3):376-382. 2015.

[08] Liwen Wang, Margaret Anne Brennan, Charles Stephen Brennan, "Chapter 28 Improving antioxidant capacity of foods: adding mushroom powder to pasta", Editor(s): Victor R. Preedy, Pathology, Academic Press, 2020, Pages 289-296, ISBN 9780128159729.

[09] de Souza Campos Junior FA, Petrarca MH, Meinhart AD, de Jesus Filho M, Godoy HT. Multivariate optimization of extraction and validation of phenolic acids in edible mushrooms by capillary electrophoresis. Food Res Int. 2019 Dec;126:108685.

[10] Shao S, Hernandez M, Kramer JK, Rinker DL, Tsao R. Ergosterol profiles, fatty acid composition, and antioxidant activities of button mushrooms as affected by tissue part and developmental stage. J Agric Food Chem. 2010 Nov 24;58(22):11616-25.

[11] Michelle Blumfield, Kylie Abbott, Emily Duve, Tim Cassettari, Skye Marshall and Flavia Fayet-Moore, Examining the health effects and bioactive components in Agaricus bisporus mushrooms: a scoping review, The Journal of Nutritional Biochemistry, Volume 84, 2020, 108453, ISSN 0955-2863.

[12] G. Jaworska and E. Bernas, "AMINO ACID CONTENT OF FROZEN AGARICUS BISPORUS AND BOLETUS EDULIS MUSHROOMS: EFFECTS OF PRETREATMENTS", International Journal of Food Properties, 16:139-153, 2013.

[13] Funda Atila, Mustafa Nadhim Owaid, Mohammad Ali Shariati, "THE NUTRITIONAL AND MEDICAL BENEFITS OF AGARICUS BISPORUS : A REVIEW", JOURNAL OF MICROBIOLOGY, BIOTECHNOLOGY AND FOOD SCIENCES, December - January 2017/18, vol. 7, no. 3, pages: 281-286.

[14] Caglarirmak N. Determination of nutrients and volatile constituents of Agaricus bisporus (brown) at different stages. J Sci Food Agric 2009;89:634-638. 
[15] Nataraj S. pagadala, Khajamohiddin Syed and Jack Tuszynski, "Software for molecular docking: a review”, Biophys Rev. 2017 Apr;9(2):91-102. doi: 10.1007/s12551-016-0247-1. Epub 2017 Jan 16.

[16] Morris GM, Lim-Wilby M. Molecular docking. Methods Mol Biol. 2008;443:365-82. doi: 10.1007/978-1-59745-177-2_19. PMID: 18446297.

[17] Gaba Monika, Gaba Punam, Singh Sarbjot, and Gupta G., "AN OVERVIEW ON MOLECULAR DOCKING”, Int.J.Drug Dev. \& Res., April-June 2010, 2(2):219-231.

[18] PyRx - Virtual Screening Tool download | SourceForge.net [last accessed on 30-April2021]

[19] BIOVIA Discovery Studio - BIOVIA - Dassault Systèmes® (3ds.com) [last accessed on 05-May-2021]

[20] PubChem (nih.gov) [last accessed on 10-May-2021]

[21] RCSB PDB: Homepage [last accessed on 12-May-2021]

[22] Uppuluri V. Mallavadhani, Akella V.S. Sudhakar, K.V.S. Satyanarayana, Anita Mahapatra, Wenkui Li, Richard B. vanBreemen, "Chemical and analytical screening of some edible mushrooms", Food Chemistry 95 (2006) 58-64.

[23] Gąsecka, M., Magdziak, Z., Siwulski, M. et al. Profile of phenolic and organic acids, antioxidant properties and ergosterol content in cultivated and wild growing species of Agaricus . Eur Food Res Technol 244, 259-268 (2018)

[24] Viraj J. Jasinghe, Conrad O. Perera, "Distribution of ergosterol in different tissues of mushrooms and its effect on the conversion of ergosterol to vitamin D2 by UV irradiation", Food Chemistry, Volume 92, Issue 3, 2005, Pages 541-546, ISSN 0308-8146

[25] Sanjeeve Balasubramaniam, Julia A. Beaver, Sara Horton, et al. FDA Approval Summary: Rucaparib for the Treatment of Patients with Deleterious BRCA MutationAssociated Advanced Ovarian Cancer, Clin Cancer Res; 23(23) December 1, 2017,71657170.

[26] Syed, Y.Y. Rucaparib: First Global Approval. Drugs 77, 585-592 (2017).

[27] Mirza MR, Monk BJ, Herrstedt J, et al. Niraparib maintenance therapy in platinumsensitive, recurrent ovarian cancer. N Engl J Med. 2016;375(22):2154-64.

[28] Scott, L.J. Niraparib: First Global Approval. Drugs 77, 1029-1034 (2017). 
[29] Li X, Wu Q, Xie Y, et al. Ergosterol purified from medicinal mushroom Amauroderma rude inhibits cancer growth in vitro and in vivo by up-regulating multiple tumor suppressors. Oncotarget. 2015;6(19):17832-17846.

[30] M. T. Ravi Subbiah and W. Abplanalp, Ergosterol Inhibits the Growth of Human Breast Cancer Cells in vitro and the Potential Role of its Oxidation Products, International Journal for Vitamin and Nutrition Research, Vol 73, No.1. 2013

\section{Appendix-}

\section{Chemical Constituents of Agaricus Bisporus-}

\begin{tabular}{|l|c|}
\hline $\mathbf{1}]$ & Ergosterol \\
\hline 2$]$ & Ergocalciferol \\
\hline 3$]$ & Folate \\
\hline $\mathbf{4}]$ & Naringenin \\
\hline $\mathbf{5}]$ & Quthocyanin \\
\hline $\mathbf{6}]$ & Myricetin \\
\hline $\mathbf{7}]$ & Kaempferol \\
\hline $\mathbf{8}]$ & Catechin \\
\hline $\mathbf{9}]$ & Resveratrol \\
\hline $\mathbf{1 0}]$ & Gamma tocopherol \\
\hline $\mathbf{1 1}]$ & Vitamin E \\
\hline $\mathbf{1 2}]$ & Riboflavin \\
\hline $\mathbf{1 3}]$ & Delta tocopherol \\
\hline $\mathbf{1 4}]$ & Beta tocopherol \\
\hline $\mathbf{1 5}]$ & Beta carotene \\
\hline $\mathbf{1 6}]$ & Chlorogenic acid \\
\hline $\mathbf{1 7}]$ & Cholecalciferol \\
\hline $\mathbf{1 8}]$ & Ferulic acid \\
\hline $\mathbf{1 9}]$ & Caffeic acid \\
\hline $\mathbf{2 0}]$ & \\
\hline
\end{tabular}




\begin{tabular}{|c|c|}
\hline 21] & Vitamin B1 \\
\hline 22] & Cinnamic acid \\
\hline 23] & p-coumaric acid \\
\hline 24] & Protocatechuic acid \\
\hline 25] & Gallic acid \\
\hline 26] & Homogentistic acid \\
\hline 27] & p-hydroxybenzoic acid \\
\hline 28] & Ascorbic acid \\
\hline 29] & Pantothenic acid \\
\hline 30] & Pyridoxamine \\
\hline 31] & Betaine \\
\hline 32] & Oleic acid \\
\hline 33] & Ergothioneine \\
\hline 34] & Niacin \\
\hline 35] & Stearic acid \\
\hline 36] & Palmitic acid \\
\hline 37] & Stearic acid \\
\hline 38] & Lycopene \\
\hline 39] & Chitin \\
\hline 40] & Alpha-glycan \\
\hline 41] & Beta glycan \\
\hline 42] & Linoleic acid \\
\hline
\end{tabular}

\section{Table 2}

Table 3 shows the binding affinity of different chemical constituents of Agaricus Bisporus and binding protein-

\begin{tabular}{|l|c|c|}
\hline \multicolumn{1}{|c|}{ Complex } & Ligands & Binding Affinity \\
\hline 4und_5280793_uff_E=685.37 & Ergocalciferol & $\mathbf{- 9 . 1}$ \\
\hline 4und_5280863_uff_E=362.50 & Kaempferol & $\mathbf{- 9 . 1}$ \\
\hline 4und_9064_uff_E=204.84 & Catechin & $\mathbf{- 8 . 9}$ \\
\hline 4und_445154_uff_E=172.22 & Resveratrol & $\mathbf{- 8 . 9}$ \\
\hline
\end{tabular}




\begin{tabular}{|c|c|c|}
\hline 4und_45356270_uff_E=272.80 & Gamma tocopherol & -8.6 \\
\hline 4und_14985_uff_E=288.57 & Vitamin E & -8.5 \\
\hline 4und_493570_uff_E=317.94 & Riboflavin & -8.3 \\
\hline 4und_92094_uff_E=239.38 & delta tocopherol & -8.3 \\
\hline 4und_6857447_uff_E=255.66 & Beta tocopherol & -8.0 \\
\hline 4und_5280489_uff_E=674.37 & Beta carotene & -7.9 \\
\hline 4und_1794427_uff_E=254.42 & Chlorogenic acid & -7.3 \\
\hline 4und_5280795_uff_E=694.85 & Cholecalciferol & -7.2 \\
\hline 4und_445858_uff_E=177.42 & Ferulic acid & -7.1 \\
\hline 4und_689043_uff_E=98.60 & Caffeic acid & -6.9 \\
\hline 4und_1130_uff_E=395.86 & Vitamin B1 & -6.7 \\
\hline 4und_444539_uff_E=86.61 & Cinnamic acid & -6.8 \\
\hline 4und_637542_uff_E=90.83 & p-coumaric acid & -6.8 \\
\hline 4und_72_uff_E=70.72 & Protocatechuic acid & -6.5 \\
\hline 4und_370_uff_E=77.82 & Gallic acid & -6.5 \\
\hline 4und_780_uff_E=96.73 & Homogentistic acid & -6.3 \\
\hline 4und_135_uff_E=62.95 & p-hydroxybenzoic acid & -6.2 \\
\hline 4und_87141792_uff_E=146.37 & Linoleic acid & -6.6 \\
\hline 4und_938_uff_E=58.73 & Niacin & -5.8 \\
\hline 4und_6613_uff_E $=133.81$ & Pantothenic acid & -5.8 \\
\hline 4und_445639_uff_E=80.35 & Oleic acid & -5.8 \\
\hline 4und_985_uff_E=57.46 & Palmitic acid & -5.6 \\
\hline 4und_54670067_uff_E=200.65 & Ascorbic acid & -5.6 \\
\hline 4und_5351619_uff_E=351.47 & Ergothioneine & -5.5 \\
\hline 4und_247_uff_E=88.22 & Betaine & -3.8 \\
\hline 4und_1054_uff_E $=125.61$ & Pyridoxamine & -5.6 \\
\hline
\end{tabular}

\section{$\underline{\text { Table } 3}$}




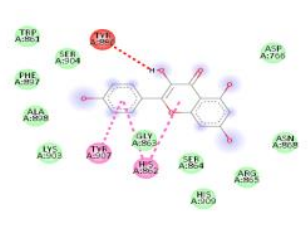

2D

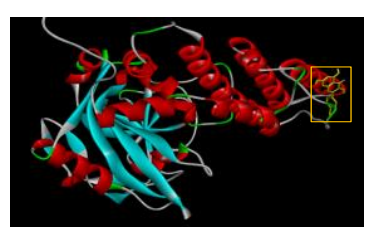

kaempferol

3D
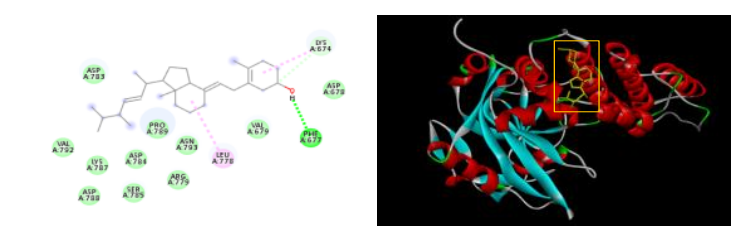

2D

Ergocalciferol

3D

2D \& 3D images of Chemical Constituents of Agaricus Bisporus binding with 4UND protein 

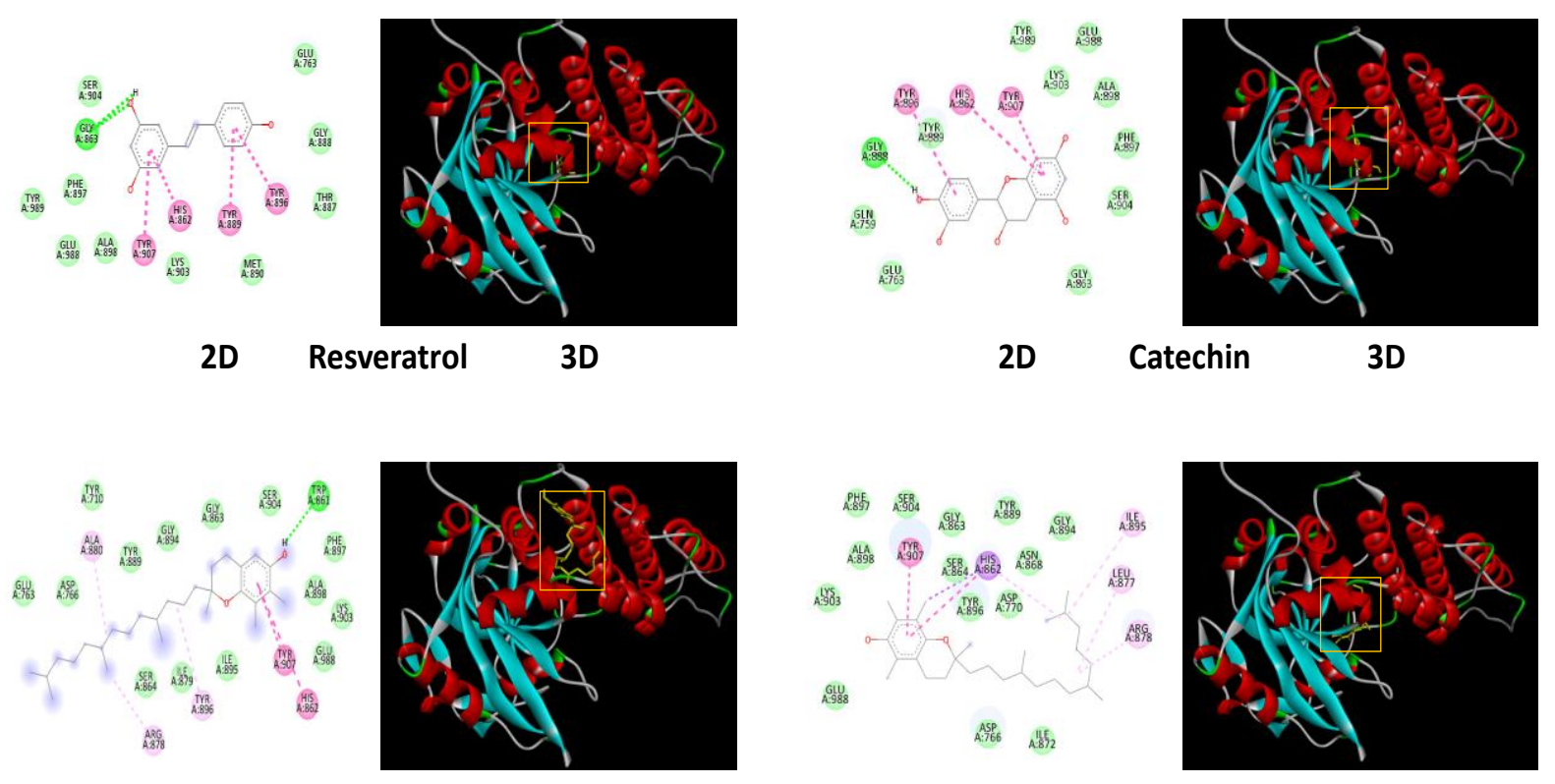

2D Gamma-tocopherol 3D

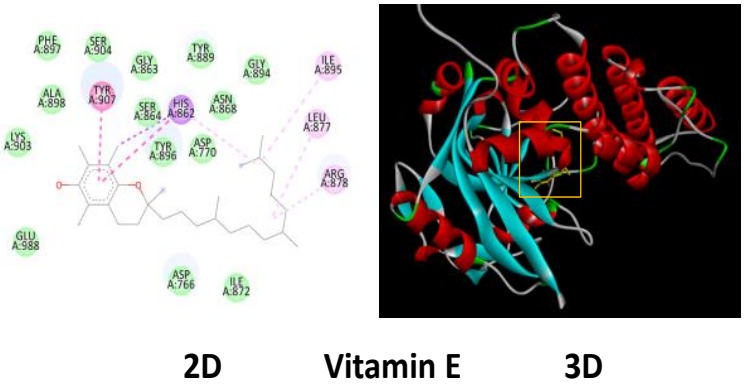

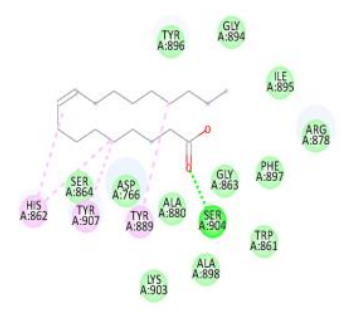

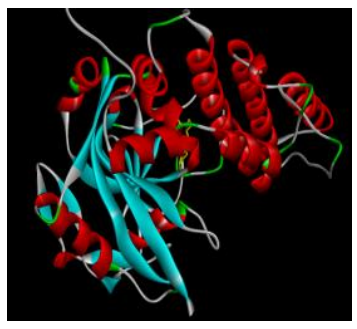

2D Cinnamic acid 3D

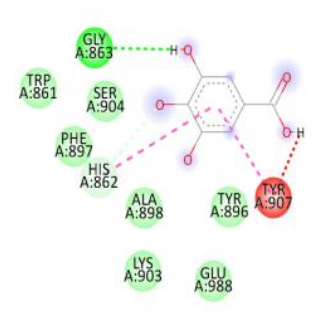

2D

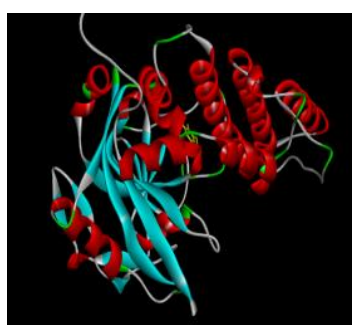

Gallic acid 3D

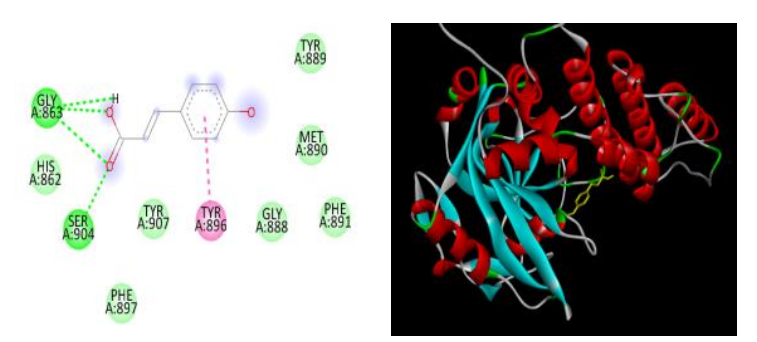

2D P-coumaric acid 3D

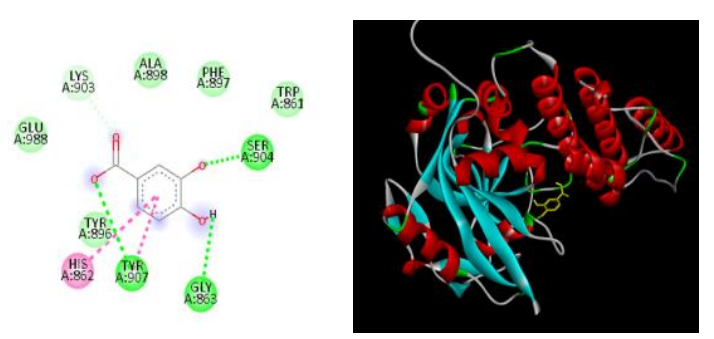

2D Protocatechuic acid 3D 

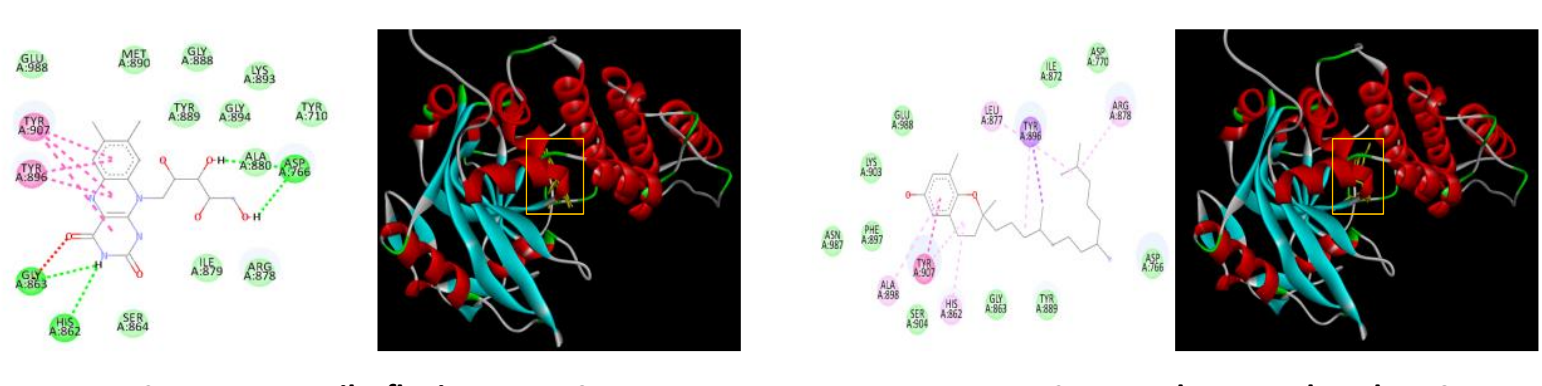

2D Riboflavin 3D

2D Delta-tocopherol 3D

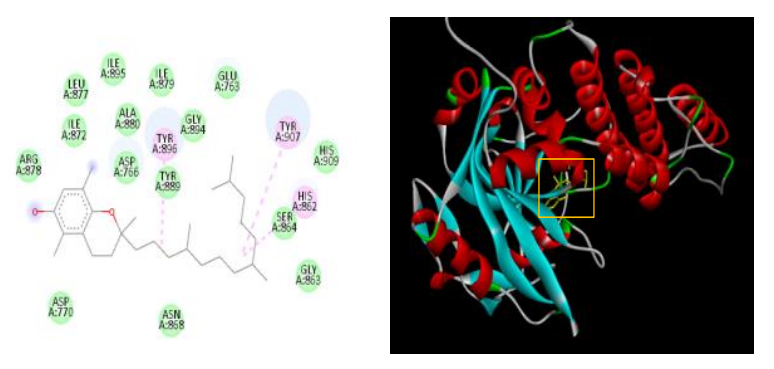

2D Beta-tocopherol 3D

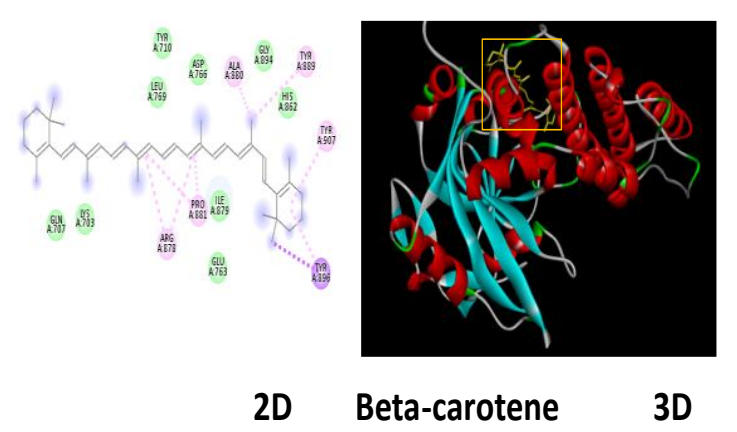

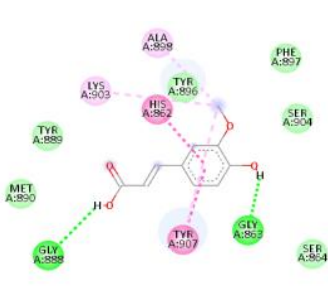

2D

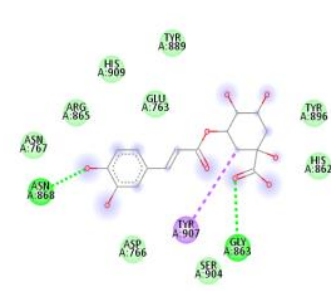

2D Chlorogenic acid

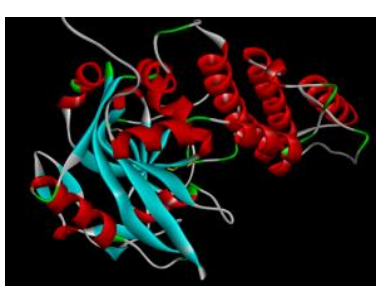

3D

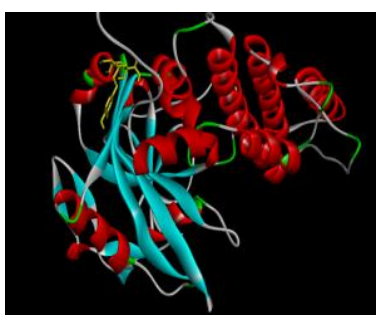

3D

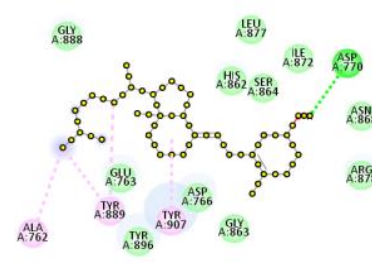

2D

Cholecalciferol 3D

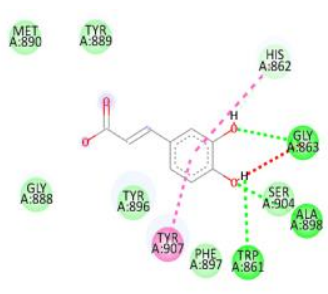

2D
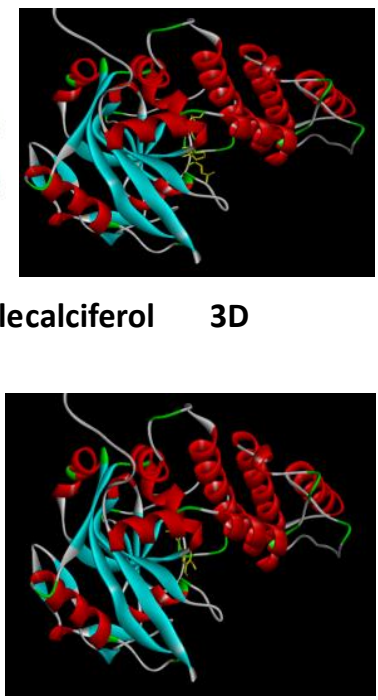

Caffeic acid

Fig. 2D \& 3D images of constituents of Agaricus Bisporus binding with 4UND protein 